\title{
The sensitivity of male rat reproductive organs to monosodium glutamate
}

\author{
Sitthichai Iamsaard ${ }^{1}$, Wannisa Sukhorum ${ }^{1}$, Rarinthorn Samrid ${ }^{1}$, Jindaporn Yimdee ${ }^{1}$, \\ Pipatphong Kanla ${ }^{1}$, Kowit Chaisiwamongkol ${ }^{1}$, Wiphawi Hipkaeo ${ }^{1}$, Duriya Fongmoon ${ }^{2}$, \\ Hisatake Kondo ${ }^{1}$
}

${ }^{1}$ Department of Anatomy, Faculty of Medicine, Khon Kaen University Khon Kaen, Thailand ${ }^{2}$ Lampang Cancer Center, Division of Medical Services, Ministry of Public Health, Lampang, Thailand

Corresponding author: Sitthichai Iamsaard Department of Anatomy Faculty of Medicine Khon Kaen University 123 Mitraparp Road Amphoe Muang Khon Kaen 40002, Thailand

Iamsaard_sitt@yahoo.com; sittia@kku.ac.th Tel.: + 6643363212

Fax.: + 6643363212

Received: 24 June 2013

Accepted: 29 November 2013

Copyright (C) 2014 by Academy of Sciences and Arts of Bosnia and Herzegovina. E-mail for permission to publish: amabih@anubih.ba

\section{Introduction}

Monosodium L- glutamate (MSG) is a major flavor enhancer used as a food additive. The concentrations of MSG used as food additive vary in different foods (1). Currently, the safe concentration of MSG in foods and its toxic-

\begin{abstract}
Objective. This study aimed to investigate the sensitivity of the testis, epididymis, seminal vesicle, and sperm acrosome reaction (AR) to monosodium L- glutamate (MSG) in rats. Materials and methods. Rats were divided into four groups and fed with non-acidic MSG at $0.25,3$ or $6 \mathrm{~g} / \mathrm{kg}$ body weight for 30 days or without MSG. The morphological changes in the reproductive organs were studied. The plasma testosterone level, epididymal sperm concentration, and sperm AR status were assayed. Results. Compared to the control, no significant changes were discerned in the morphology and weight of the testes, or the histological structures of epididymis, vas deferens and seminal vesicle. In contrast, significant decreases were detected in the weight of the epididymis, testosterone levels, and sperm concentration of rats treated with $6 \mathrm{~g} / \mathrm{kg}$ body weight of MSG. The weight loss was evident in the seminal vesicle in MSG-administered rats. Moreover, rats treated with MSG 3 and $6 \mathrm{~g} / \mathrm{kg}$ exhibited partial testicular damage, characterized by sloughing of spermatogenic cells into the seminiferous tubular lumen, and their plasma testosterone levels were significantly decreased. In the $6 \mathrm{~g} / \mathrm{kg}$ MSG group, the sperm concentration was significantly decreased compared with the control or two lower dose MSG groups. In AR assays, there was no statistically significant difference between MSG-rats and normal rats. Conclusion. Testicular morphological changes, testosterone level, and sperm concentration were sensitive to high doses of MSG while the rate of AR was not affected. Therefore, the consumption of high dose MSG must be avoided because it may cause partial infertility in male.
\end{abstract}

Key words: Monosodium L- glutamate (MSG), Testis, Testosterone, Sperm acrosome reaction.

ity in human is still a controversial issue (2). In animals, MSG at higher doses was demonstrated to be a neurotoxic salt that could alter the hypothalamic-pituitary-adrenal axis (HPA) and damage neurons in the hypothalamic nuclei (3-6). In addition, the damages 
of liver and kidney could be induced by excessive MSG administration (7). Those findings imply that free glutamate dissociated from MSG may act on their specific receptors in the central neurons or some peripheral cells, resulting in their pathological alterations.

There have recently been several reports indicating that administration of MSG may affect the sperm count in both neonatal and adult animals (8-11) and the glutamate receptors and transporters are expressed in the testis and sperm of mice, rats, and humans (12, 13). However, the roles of glutamate receptors present in male reproductive organs, including the sperm, have not been elucidated. Moreover, no systemic examination of male reproductive organs and of the sperm physiology, such as endogenous sperm capacitation and acrosome reaction MSG-treated rats in various doses, has been performed. Therefore, this study attempted to examine the sensitivity of the entire male reproductive system and the sperm acrosome reaction to varied doses of MSG administration.

\section{Materials and methods}

\section{Animals and treatment}

Sprague-dawley male rats (8-week-old) were purchased from the Laboratory Animal Unit, Faculty of Medicine, Khon Kaen University, Khon Kaen, Thailand. Thirty-two animals were randomly divided into 4 groups $(\mathrm{n}=8$ for each) and kept in groups of four in cages $(60 \times 30 \times 20)$ with food and water available ad libitum. The control group was treated with distilled water (vehicle) and the treated groups were administered with non-acidic MSG solutions at concentrations of $0.25(\mathrm{pH}$ 7.3), 3 (pH 7.17), and 6 (pH 7.24) g/kg body weight, daily, by gavages for 30 days. The selected doses were based on the toxicity levels reported by previous authors $(14,15): 0.25$ $\mathrm{g} / \mathrm{kg}$ body weight for non-toxic dose MSG, 3 and $6 \mathrm{~g} / \mathrm{kg}$ body weight for slightly toxic and highly toxic doses, respectively. The animals received twice a day (between 0 and $8 \mathrm{~h}$ ) half of the given concentrations of MSG for each feeding period to avoid damage to the rat's stomach from single excess administration of MSG, resulting in unhealthy animals (our preliminary results). This study was approved by the Animal Ethics Committee of Khon Kaen University, based on the Ethics of Animal Experimentation of the National Research Council of Thailand (ref. no. 0514.1.12.2/70).

\section{Morphological study}

On the day after the termination of MSG administration, all the animals were euthanized by cervical dislocation and gently sacrificed to collect the male reproductive organs (testes (TE), epididymis (EP), vas deferens (VD), and seminal vesicle (SV). Then, the organs of all groups were observed for gross lesions, recorded in color photography, and were subsequently removed, cleaned of fats, and weighed. Tissues of TE, EP with VD, and SV were extirpated from the right side and they were fixed with 10\% formalin in PBS (pH 7.4), and embedded in paraffin, and sectioned at 4-6 $\mu \mathrm{m}$ thick and stained with hematoxylin-eosin ( $\mathrm{H}$ and $\mathrm{E})$. All images were captured by a Nikon light ECLIPSE E200 microscope equipped with a DXM1200 digital camera.

\section{Plasma testosterone assay}

Plasma testosterone concentration was measured by enzymatic immunoassay performed in the facilities of the radiology unit of Srinagarind Hospital, Faculty of Medicine, Khon Kaen University.

\section{Sperm count and acrosome reaction assay}

Rat sperms were collected from the left caudal epididymis plus vas deferens and placed into $1 \mathrm{ml}$ phosphate buffered saline (PBS, $37^{\circ} \mathrm{C}, \mathrm{pH} 7.4$ ) and further centrifuged $\left(500 \mathrm{xg}, 37^{\circ} \mathrm{C}, 5 \mathrm{~min}\right.$.) to separate the sperm 
pellet from the epididymal fluid. For epididymal sperm concentration analysis, the sperm pellets were re-suspended with $1 \mathrm{ml}$ potassium-enriched simplex optimized medium (KSOM) and supplemented (EmbryoMax KSOM Powdered Mouse Embryo Culture Medium; Millipore catalogue number: R-MR-020P-5D) with $0.3 \%$ bovine serum albumin (BSA). The sperm solutions (1:20 dilution) were counted according to the standard procedure in a Neubauer counting chamber (16). To evaluate the percentage of the endogenous acrosome reaction (AR), a small aliquot of the sperm suspension was subjected to Coomassie blue staining as previously described (16-19).

\section{Statistical analysis}

One-way ANOVA and Student's t-test were used to examine the significant differences between two or more sets of data, and between two data points, respectively, using the program of Sigma Stat version 3.1.1. All quantitative results are presented as the mean \pm SD.

\section{Results}

\section{Morphology and weight of male reproductive organs}

In comparison with the control group, no marked differences were found in the size, shape, and surface features of the testes among the groups of rats treated with all doses of MSG (Figure 1a). In contrast, the epididymis plus vas deferens (Figure $1 \mathrm{~b}$ ) and the seminal vesicle (Figure 1c) of rats treated with $6 \mathrm{~g} / \mathrm{kg}$ MSG were smaller than those of the control, as well as the two rat groups treated with 0.25 , and $3 \mathrm{~g} / \mathrm{kg}$ body weight of MSG (Figures $1 \mathrm{~b}$ and 1c).
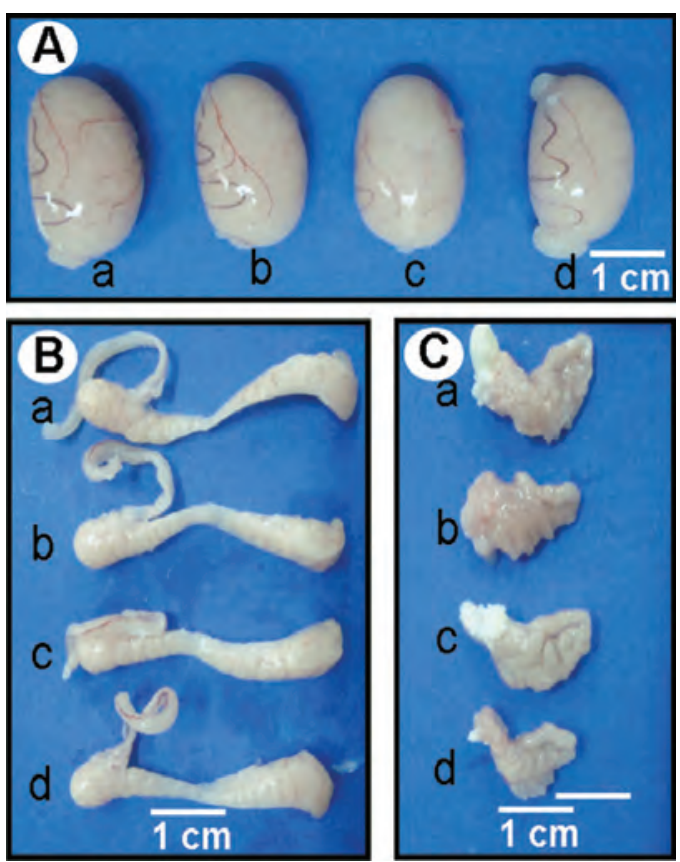

Figure 1 Photographs showing the gross morphology of right testis (A), epididymis and vas deferens (B), and seminal vesicle at right side (C) from control (a) and treated rats with MSG at 0.25 (b), 3 (c) and 6 (d) $\mathrm{g} / \mathrm{kg}$ body weight.

The weight of the different organs from the different groups was measured (Table 1). No significant differences were found among testes of any groups administered MSG as compared with the control group $(\mathrm{p}>0.05)$

Table 1 The effect of monosodium glutamate on testicular, epididymis plus vas deferens, or seminal vesicle weight $(\mathrm{g})$ in rats (mean $\pm \mathrm{SD}, \mathrm{n}=8$ in each group)

\begin{tabular}{llll}
\hline \multirow{2}{*}{ Groups } & Weights $(\mathrm{g})$ & & \\
\cline { 2 - 4 } & Testes & Epididymis plus vas deferens & Seminal vesicle \\
\hline Control & $1.6829 \pm 0.05$ & $0.5068 \pm 0.01$ & $0.8769 \pm 0.04$ \\
$0.25 \mathrm{~g} \mathrm{SG} / \mathrm{kg} / \mathrm{BW}$ & $1.6812 \pm 0.03$ & $0.4803 \pm 0.02$ & $0.6836 \pm 0.07^{*}$ \\
$3 \mathrm{~g} \mathrm{MSG} / \mathrm{kg} / \mathrm{BW}$ & $1.5988 \pm 0.06$ & $0.4727 \pm 0.01$ & $0.6579 \pm 0.06^{*}$ \\
$6 \mathrm{~g} \mathrm{MSG} / \mathrm{kg} / \mathrm{BW}$ & $1.5874 \pm 0.04$ & $0.4283 \pm 0.02^{*}$ & $0.3904 \pm 0.08^{* *}$ \\
\hline
\end{tabular}

$\mathrm{BW}=$ body weight; ${ }^{*} \mathrm{p}<0.05 ;{ }^{*} \mathrm{p}<0.01$. 
(Figure 1 and Table 1). The weight of the epididymis plus vas deferens was significantly decreased only in the $6 \mathrm{~g} / \mathrm{kg}$ body weight of MSG group as compared with the control $(p<0.05)$, while the weight of the seminal vesicle decreased in all MSG-treated groups with a marked decrease in the $6 \mathrm{~g} / \mathrm{kg}$ body weight of MSG group $(\mathrm{p}<0.01)$.

\section{The effect of MSG on testicular histology}

No marked changes in histology were noted in the testes of rats receiving $0.25 \mathrm{~g} / \mathrm{kg}$ body weight of MSG as compared with the control group (Figure 2a and 2b). However, a mild slouching of spermatogenic cells in the seminiferous tubular lumen was observed in approximately $10-15 \%$ of the seminiferous tubules obtained from eight animals administered with $3 \mathrm{~g} / \mathrm{kg}$ body weight of MSG (Figure $2 \mathrm{c}$ ). Moreover, mild sloughing of such seminiferous tubules with some vacuolization and some shrinkage of the interstitial tissues with wider empty spaces were noticed in approximately $40-45 \%$ of rats administered with $6 \mathrm{~g} / \mathrm{kg}$ body weight of MSG (Figure 2d).

\section{Effect of MSG on plasma testosterone}

When compared to the control, the plasma testosterone levels were significantly lowered in $3 \mathrm{~g} / \mathrm{kg}$ body weight of MSG $(\mathrm{p}<0.05)$ and of $6 \mathrm{~g} / \mathrm{kg}$ body weight of MSG $(\mathrm{p}<0.01)$, whereas the testosterone levels in rats with $0.25 \mathrm{~g} / \mathrm{kg}$ body weight of MSG were normal ( $>0.05$ ) (Figure 3).

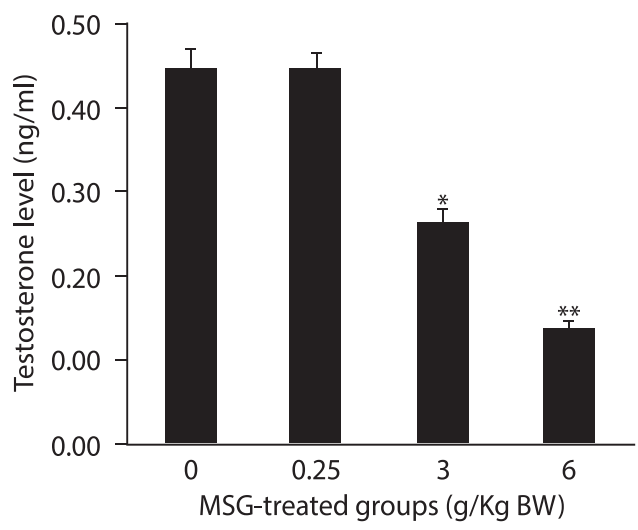

Figure 3 Testosterone plasma levels $(\mathrm{ng} / \mathrm{ml}$ ) determined after treatment in control and MSG treated groups $(0.25,3$ and $6 \mathrm{~g} / \mathrm{kg}$ body weight, respectively). Statistically significant difference from control $\left({ }^{*} p<0.05 ;{ }^{* *} p<0.01\right)$.

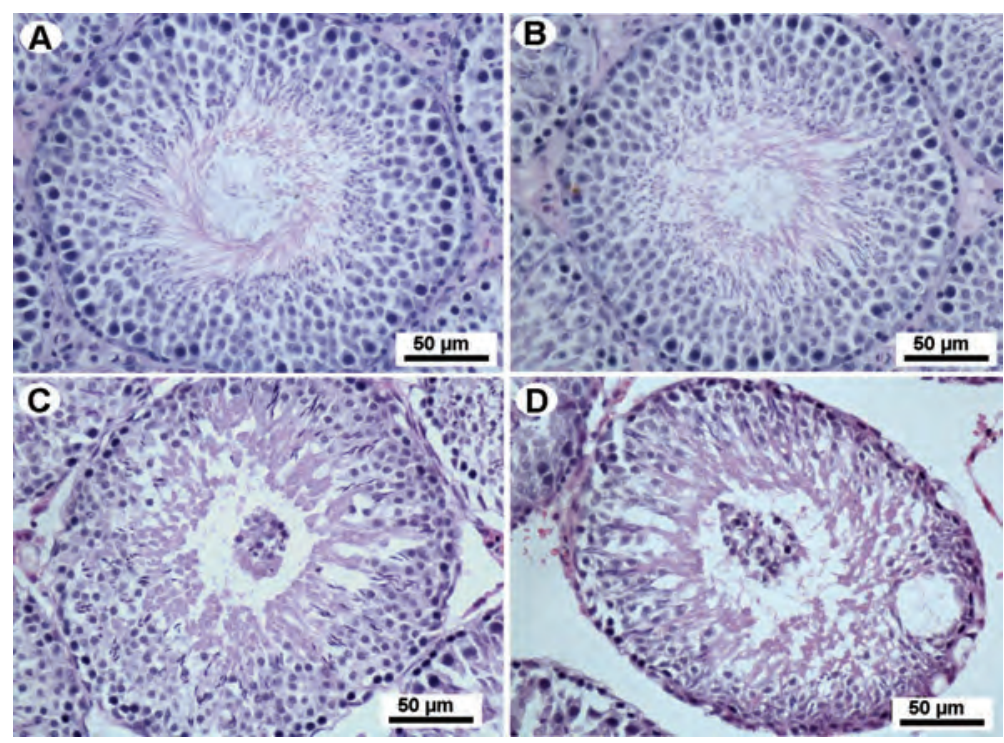

Figure 2 Light microscopy of the seminiferous tubules from rats treated with or without MSG. (A) Control group. (B, C, and D) MSG treated groups (0.25, 3 and $6 \mathrm{~g} / \mathrm{kg}$ body weight, respectively). Note: slouching of spermatogenic cells in the lumen of seminiferous tubules were observed only in MSG treated groups at 3 (C) and 6 (D) g/ kg body weight. 
Table 2 The effect of monosodium glutamate on epididymal sperm concentration and acrosome reaction in rats

\begin{tabular}{llll}
\hline & & \multicolumn{2}{l}{ Effect of monosodium glutamate } \\
\cline { 3 - 4 } Groups & $\mathrm{n}$ & $\begin{array}{l}\text { Epididymal sperm concentration } \\
\left(\times 10^{6} \text { sperm/ml; mean } \pm \text { SD }\right)\end{array}$ & Acrosome reacted sperm (\%) \\
\hline Control & 8 & $36.88 \pm 2.40$ & 4.1 \\
$0.25 \mathrm{~g} \mathrm{MSG} / \mathrm{kgBW}$ & 8 & $34.25 \pm 4.01$ & 5.7 \\
$3 \mathrm{~g} \mathrm{MSG} / \mathrm{kgBW}$ & 8 & $36.93 \pm 3.09$ & 6.4 \\
$6 \mathrm{~g} \mathrm{MSG} / \mathrm{kgBW}$ & 8 & $24.70 \pm 6.02^{*}$ & 4.4 \\
\hline
\end{tabular}

$\mathrm{BW}=$ body weight; ${ }^{*} \mathrm{p}<0.05$.

\section{Sensitivity of sperm count to MSG}

The epididymal sperm concentration and the percentages of sperms representing the endogenous acrosome reaction are shown in Table 2. The administration of 0.25 and $3 \mathrm{~g} / \mathrm{kg}$ body weight of MSG did not affect the epididymal sperm concentration when compared with the control group. In contrast, the epididymal sperm concentration was significantly decreased in the $6 \mathrm{~g} / \mathrm{kg}$ body weight of the MSG group, compared with the control or two lower dose MSG groups. In the acrosome reaction assays, there was no statistically significant difference between the control and three different MSG treated groups ( $p>0.05$ ).

\section{Discussion}

Our morphological findings indicate that the epididymis plus vas deferens and, in particular, the seminal vesicles, but not the testes, are very sensitive to MSG administrations. In accordance with this finding, a previous study showed that the oral administration of $4 \mathrm{~g} / \mathrm{kg}$ body weight of MSG did not affect the testicular morphology (11).

França et al., (9) reported histological alterations of the testes in prepubertal $4 \mathrm{mg} / \mathrm{kg}$ body weight of MSG rats and found a significant reduction of spermatogenic cells (SCs) in the testes of adult MSG rats. Their finding of SCs is supported by our present finding that these SCs were sloughing into seminiferous tubule lumen (Fig $2 \mathrm{c}$ and $2 \mathrm{~d}$ ). In a previous study, the expressions and localizations of metabotropic glutamate ( $\mathrm{mGlu}$ ) receptors were demonstrated in both rat and human testicular tissues, particularly in SCs (12). It is possible that excessive glutamate dissociated from exogenously administered MSG rats may hyper-activate the mGlu receptors present in SCs, resulting in an excess of calcium influx, which may induce such testicular pathological changes as sloughing of SCs into the tubular lumen. In contrast to the testes, the epididymis plus vas deferens and the seminal vesicle exhibited no marked changes in histology in all the MSG treated groups, when compared to the control (data not shown).

MSG has been demonstrated to exert neuronal toxic effects in the central nervous system (CNS), including the hypothalamopituitary (HP) axis $(3,20-23)$. The plasma levels of gonadotropic hormones (FSH and $\mathrm{LH}$ ) and testosterone, and the total number of Leydig cells have been reported to be significantly decreased in prepubertal rats treated with $4 \mathrm{mg} / \mathrm{kg}$ body weight of MSG (9). In adult male rats, it has been shown that administration of $4 \mathrm{~g} / \mathrm{kg}$ body weight of MSG significantly decreased the plasma testosterone level (11). The present reduction in the plasma testosterone levels may therefore be due to the disruption of the HP axis in the MSG treated rats. In addition, it 
is possible that the total number of Leydig cells responsible for testosterone production may decrease, as suggested by the marked shrinkage of the testicular interstitial tissues of the MSG groups (Figure $2 \mathrm{c}$ and $2 \mathrm{~d}$ ) compared to the control (Figure 2a). The quantitative comparison of the number of Leydig cells among MSG-rats and normal rats remains to be investigated.

The present decreased epididymal sperm concentration in rats treated with a high dose MSG ( $6 \mathrm{~g} / \mathrm{kg}$ body weight) is consistent with previous studies (9-11). In addition, our results further demonstrated decreases in the size and weight of the epididymis, some histological changes in the testes, and a depletion of plasma testosterone hormone in rats treated with a high dose of MSG. Since the localization of glutamate receptors and transporters have been reported in animal and human sperms (13), it is possible to expect that free exogenous glutamates dissociated from MSG are released into the epididymal fluid and may enhance the acrosome reaction through the glutamate receptors and transporters. However, no significant difference was found in the rate of the acrosome reacted sperm in all groups (Table 2). One of the possible explanations for this negative finding is that the epididymal sperms were masked with some epididymal molecules in a way similar to that preventing the pre-capacitation or pre-acrosome reaction factors, resulted in the inability of free glutamates to act on their receptors or transporters, allowing the acrosome reaction process.

\section{Conclusion}

In conclusion, our study examined histopathological changes in the seminiferous tubules of rats that received various doses of MSG. The decrease of testosterone and epididymal sperm concentration may depend on the level of the MSG dose. Although glutamate receptors and transporters have been localized in the mature sperm, their functions responsible for acrosome reaction are not elucidated. To clarify this function, the percoll gradient-centrifuged (PGC) $\mathrm{Ca}-$ pacitated sperm (free from masking of the epididymal molecules) may be used, incubated with purified glutamate, to investigate whether glutamate could induce acrosome reaction or not. In this study, we first examined the endogenous sperm acrosome reaction status in MSG-treated rats. The analysis of the amount of free glutamate present in the epididymal fluid of MSG rats and the in vitro acrosome reaction assay by incubation with washed epididymal sperms and pure glutamate need to be further clarified.

Authors' contributions: Conception and design: SI, WH, HK; Acquisition, analysis, and interpretation of data: SI, WS, JY, PK, DF; Drafting the article: SI, WS, HK; Revising it critically for important intellectual content: SI, HK, WS.

Acknowledgements: This project was supported by Invitation Research Grant 2012, Faculty of Medicine (No. I-55102), Khon Kaen University, Thailand.

Conflict of interest: The authors declare that they have no conflict of interest.

\section{References}

1. Walker R, Lupien JR. The safety evaluation of monosodium glutamate. J Nutr. 2000;130(4S Suppl):1049S-52S.

2. Beyreuther K, Biesalski HK, Fernstrom JD, Grimm P, Hammes WP, Heinemann U, et al. Consensus meeting: monosodium glutamate - an update. Eur J Clin Nutr. 2007;61(3):304-13.

3. Olney JW, Sharpe LG. Brain lesions in an infant rhesus monkey treated with monosodium glutamate. Science. 1969;166:386-8.

4. Pizzi WJ, Barnhart JE, Fanslow DJ. Monosodium glutamate administration to the newborn reduces reproductive ability in female and male mice. Science. 1977;196:452-4.

5. Nemeroff CB, Lamartiniere CA, Mason GA, Squibb RE, Hong JS, Bondy SC. Marked reduction in gonadal steroid hormone levels in rats treated neonatally with monosodium L-glutamate: Fur- 
ther evidence for disruption of hypothalamicpituitary-gonadal axis regulation. Neuro-endocrinology. 1981;33:265-7.

6. Seo HJ, Ham HD, Jin HY, Lee WH, Hwang HS, Park SA, et al. Chronic administration of monosodium glutamate under chronic variable stress impaired hypothalamic-pituitary-adrenal axis function in rats. Korean J Physiol Pharmacol. 2010;14:213-21.

7. Ortiz GG, Bitzer-Quinter OK, Beas Zárate C, Rodríguez-Reynoso S, Larios-Arceo F, VelázquezBrizuela IE, et al. Mono-sodium glutamate-induced damage in liver and kidney: a morphological and bio- chemical approach. Biomed Pharmacother. 2006;60:86-91.

8. Lamperti A, Blaha G. The effects of neonatallyadministered monosodium glutamate on the reproductive system of adult hamsters. Biol Reprod. 1976;14:362-9.

9. França LR, Suescun MO, Miranda JR, Giovambattista A, Perello M, Spinedi E, et al. Testis structure and function in a nongenetic hyperadipose rat model at prepubertal and adult ages. Endocrinol. 2005;147(3):1556-63.

10. Nayanatara AK, Vinodini NA, Damodar G, Ahemed B, Ramaswamy CR, Shabarianth, et al. Role of ascorbic acid in monosodium glutamate mediated effect on testicular weight, sperm morphology and sperm count, in rat testis. JCCM. 2008;3(1):1-5.

11. Igwebuike UM, Ochiogu IO, Ihedinihu BC, Ikokide JE, Idika IK. The effects of oral administration of monosodium glutamate $(\mathrm{msg})$ on the testicular morphology and cauda epididymis sperm reserves of young and adult male rat. Vet Arhiv. 2011;81(4):525-34.

12. Storto M, Sallese M, Salvatore L, Poulet R, Condorelli DF, Dell'Albani P, et al. Expression of metabotropic glutamate receptors in the rat and human testis. J Endocrinol. 2001;170:71-8.

13. Hu JH, Yang N, Ma YH, Jiang J, Zhang JF, Fei J, et al. Identification of glutamate receptors and transporters in mouse and human sperm. J. Androl. 2004;25(1):140-6.
14. Bogdanov MB, Wurtman RJ. Effects of systemic or oral ad libitum monosodium glutamate administration on striatal glutamate release, as measured using microdialysis in freely moving rats. Brain Res.1994;660:337-40.

15. Eweka AO, Om'Iniabohs FAE. Histological studies of the effects of monosodium glutamate on the testes of adult Wistar rats. Internet J Urol. 2008;5(2):1-8.

16. Iamsaard S, Vanichviriyakit R, Hommalai G, Seawu A, Srakaew N, Withyachum Narnkul B, et al. Enzymatic activity of sperm proprotein convertase is important for mammalian fertilization. J Cell Physiol. 2011;226:2817-26.

17. Tanphaichitr N, Hansen C. Production of motile acrosome-reacted mouse sperm with nonomolar concentration of calcium ionophore A23187. Mol Reprod Dev. 1994;37:326-34.

18. Bendahmane M, Zeng HT, Tulsiani DR. Assessment of acrosomal status in rat spermatozoa: studies on carbohydrate and non-carbohydrate agonists. Arch Biochem Biophys.2002;404(1):38-47.

19. Iamsaard S, Prabsattroo T, Sukhorum W, Wattanathorn J, Muchimapura S, Thukhammee W. Anethum graveolens Linn. (dill) Extract Enhances the Mounting Frequency and Level of Testicular Tyrosine Protein Phosphorylation in Rats. J Zhejiang Univ Sci B. 2013;14 (3):247-52.

20. Everly JL. Light microscopy examination of monosodium glutamate induced lesions in the brain of fetal and neonatal rats. Anat Rec. 1971;169:312.

21. Miśkowiak B, Partyka M. Effects of neonatal treatment with MSG (monosodium glutamate) on hypothalamo -pituitary-thyroid axis in adult male rats. Histol Histopathol. 1993;8(4):731-4.

22. Magariños AM, Estivariz F, Morado MI, De Nicola AF. Regulation of the central nervous systempituitary-adrenal axis in rats after neonatal treatment with monosodium glutamate. Neuroendocrinology. 1988;48:105-11.

23. Samuels A. The toxicity/safety of MSG; A study in suppression of information. Account Res. 1999;6(4):259-310. 